\title{
El Partenariado Público y Privado
}

\author{
Maria Alessandra Sandulli \\ Profesora de Derecho Administrativo Facultad de Derecho. Università degli Studi di RomaTRE \\ masandulli@alice.it \\ Recibido: I 7 de febrero de 2011 \\ Aceptado: 18 de julio de 2012
}

\section{Resumen}

El artículo examina el delicado tema de la evolución de la disciplina de la asociación (partenariado) públicoprivada institucionalizada en Italia. Tras unas breves observaciones generales sobre esta institución, el autor se concentra en la gestión que hacen los servicios públicos locales de la misma, analizando en particular el paso del artículo 23 bis del Decreto-ley n. ${ }^{\circ} 112$ de 2008 a las reformas legislativas del 2011 y de enero 2012 , a favor de una más amplia privatización y liberalización de estos servicios en línea con la intención expresada por el Gobierno italiano en la Unión Europea en octubre de 2011. En las conclusiones se pone de manifiesto la cuestión de la compatibilidad constitucional de una decisión que contrasta con el resultado del referéndum del 12 y 13 de junio de 2011 que, independientemente del conocimiento de los votantes, ha expresado sus deseos de derogar los artículos a favor de la competencia, de acuerdo con el artículo 23 bis del Decreto-Ley n. ${ }^{\circ} 112$ del 2008 (y modificaciones posteriores) y en su reglamento de aplicación. Servicios público locales (Partenariado) colaboración público-privada, institucionalizado. Competición.

\section{Palabras clave}

Liberación, privatización, exclusividad, evidencia pública, benchmarking.

\section{Public-Private Partnership}

\begin{abstract}
The article examines the sensitive subject of the evolution in the discipline of institutionalised public-private (partnership) association in Italy. After a few brief general observations on this institution, the author focuses on how the local public services manage it, particularly analysing the step from article 23bis of Decree-Lawno. 112 of 2008 to the legislative reforms of 2011 and of January 2012 in favour of a more comprehensive privatisation and liberalisation of such services in line with the intention expressed by the Italian government at the European Union in October 2011. The conclusions underscore the issue of the constitutional compatibility of a decision that stands in contrast to the result of the referendum held on 12 and 13 June 2011 that, regardless of the voters' knowledge, has expressed their wish to repeal the articles in favour of competition, in accordance with article 23 bis of Decree-Law no. 112 of 2008 (and subsequent modifications) and its applicable regulation. Local public services, (Partnership) public-private collaboration, institutionalised. Competition.
\end{abstract}

Key words

Liberalisation, privatisation, exclusivity, public evidence, benchmarking. 


\section{INTRODUCCIÓN}

En la época de la crisis económico-financiera y de la tan reclamada exigencia de máxima privatización y liberalización de los servicios públicos y de las actividades gestionadas tradicionalmente por sujetos públicos, la atención hacia el tema del partenariado público-privado evidentemente es máxima, toda vez que es también indudable el condicionamiento que la disciplina del partenariado societario recibe por el contexto político, económico y social. Al igual que la necesidad de nuevas inversiones para la modernización de las redes favoreció en los años noventa la difusión de las sociedades por acciones (spa) mixtas en el ámbito local, la exigencia de contención de costes y de restablecimiento de las condiciones de competencia e igualdad entre empresas públicas y privadas en el mercado de los contratos y de los servicios públicos justifica el especial énfasis con el que, desde 2005, las nuevas normas aspiran a dicho modelo, definiendo sus límites objetivos y organizativos.

Todo ello ante una expansión más general de las formas "contractuales" de colaboración, desde los acuerdos hasta la financiación de proyectos, pasando por las concesiones de obras y servicios, hasta el arrendamiento financiero y el global service.

El elemento que caracteriza al partenariado, bien subrayado por una doctrina reciente, ${ }^{1}$ es el mantenimiento de una relación de coalición entre lo público y lo privado, que evidentemente falta en las externalizaciones (caracterizadas por su tendencia a la responsabilización autónoma, organizativa y de gestión de lo privado) y en las meras participaciones, mientras que no es siempre ajena (y según algunos autores es más bien inherente) a la relación de subsidiariedad (baste con pensar en las varias formas de acreditación de estructuras asistenciales o sanitarias).

Al lado de la distinción tradicional entre el partenariado llamado contractual (al que se refiere, por mencionar a título de ejemplo algunos modelos, el Art. 3, párrafo 15ter, del Código de los contratos) y el partenariado llamado institucional (que, en la concepción comunitaria, "implica la creación de una entidad controlada conjuntamente por el socio público y el socio privado" con objeto de asegurar la realización de una obra o la gestión de servicios públicos), hay que destacar el diferente enfoque de quien², apartándose de la reconstrucción del partenariado como modelo de acción administrativa, vinculado a opciones políticas estrictamente ligadas al modelo de Estado, pone más bien el acento en el grado de integración y de estabilidad que, con independencia de la creación de un sujeto autónomo de las administraciones públicas, caracteriza en algunos modelos la colaboración entre lo público y lo privado: el ejemplo expuesto es el del global service, al que se contrapone la separación de cometidos de las sociedades mixtas diseñadas para la gestión de los servicios públicos locales, con la imposición de la obligación de la licitación para la elección del socio con "tareas operativas específicas".

Lo que indudablemente destaca en los numerosos estudios de la materia es la dificultad sustancial de reconstruir las líneas comunes de un modelo al que se remiten figuras no homogéneas y a menudo "híbridas", según demuestra el debate nunca acabado sobre la naturaleza de las sociedades con participación pública y sobre la responsabilidad de sus administradores y empleados, o el conflicto no resuelto sobre el juez competente para resolver las controversias que les afectan, puesto de relieve eficazmente por la mejor doctrina ${ }^{3}$, a la que se debe el esfuerzo admirable de identificar los principios procedimentales comunes a las diversas formas de partenariado.

En relación con dicho conflicto se mencionan la muy reciente Sentencia del Tribunal de Casación $n^{\circ} 28329$ del 22 de diciembre de 2011 que, tras haber afirmado la naturaleza de organismo de derecho público de la RAI (Sociedad pública concesionaria del servicio radiotelevisivo), si bien calificada contextualmente como "empresa" pública, ha subrayado su diferencia con respecto a las administraciones públicas (definidas en el Art. 1 del D.L., $\mathrm{n}^{\circ} 165$ de 2001), excluyendo la sumisión a la jurisdicción exclusiva del juez administrativo de las controversias relacionadas con actos que no se pueden reconducir al ejercicio del poder público y, en antítesis con la posición expresada en la Sección VI del Consejo de Estado, ha afirmado la jurisdicción del juez ordinario sobre las controversias en contra de las selecciones establecidas por la RAI para la identificación de un grupo de periodistas idóneos, para futuras contrataciones; o también la Sentencia de la Adunanza plenaria (Sesión plenaria) nº 16 de 2011, que, al confirmar la reconstrucción sostenida repetidamente por quien escribe ${ }^{4}$, ha subrayado la distinción entre empresa pública y organismo de derecho público, excluyendo que a la primera le sea reconducible a la obligación del cumplimiento

1 F. Cortese, en de F. Mastragostino (Dir.) La collaborazione pubblico-privato e l'ordinamento amministrativo, Turín, Giappichelli, $2011,35$.

2 M. Dugato, en F. Mastragostino (Dir.), La collaborazione, cit., 55.

3 F. Mastragostino, en F. Mastragostino (Dir.), La collaborazione, cit., 71.

4 La tesis, proyectada inicialmente en el artículo de M.A. Sandulli, Imprese pubbliche e attività estranee ai settori esclus: problemi e spunti di riflessione, en M.A. Sandulli (Dir.), Organismi e imprese pubbliche, Milán, Giuffrè 2004, se ha desarrollado de una forma más amplia después en el capítulo sobre la empresa pública en II nuovo diritto degli appalti pubblici nella direttiva $2004 / 18$ CE e nella legge comunitaria n. 62/2005, dirigido por R. Garofoli y M.A. Sandulli, Milán, Giuffrè, 2005, 207 y sig., y también en Impresa pubblica e regole di affidamento dei contratti, Informe sobre el congreso relacionado con Il regime giuridico dell'impresa pubblica, que tuvo lugar en la Università di Roma Tre el 24 de enero de 2008, en www.federalismi.it. 
de los procedimientos de concurrencia pública para las actividades ajena al sector especial de pertenencia, con la consiguiente devolución de las controversias correspondientes a la jurisdicción ordinaria.

\section{CONSIDERACIONES GENERALES SOBRE EL PARTENARIADO PRIVADO INSTITUCIONALIZADO}

Después de esta necesaria introducción de tipo general, merece la pena concentrar la atención en las sociedades mixtas (forma típica del partenariado público privado institucionalizado). La fórmula, que se diferencia tanto de la asignación por concesión a terceros 5 como del modelo de la llamada gestión in house, indica, según se recuerda arriba, el fenómeno de la constitución de una sociedad mixta entre administraciones públicas y socios privados cuyo objeto es asegurar la realización de una obra o la gestión de servicios públicos: la figura, al constituir una modalidad organizativa suplementaria para la satisfacción de las exigencias generales, hace que la respuesta institucional a determinadas exigencias sea más flexible y pueda resultar -si se enmarca en los cánones del cumplimiento pleno de los principios euro-unitarios- de especial eficacia, al menos en ciertos casos (véase textualmente Cons. St., II, opinión del 18 de abril de 2007, n 456, cit., citando expresamente el Libro Verde de la Comisión Europea del 30 de abril de 2004 y la Resolución del Parlamento Europeo del 26 de octubre de 2006). Contrariamente a lo que ocurre en la concesión a terceros ${ }^{5}$, en el modelo de coparticipación societaria (también calificado en derecho como "concesión ejercida en forma de sociedad": Cons. St., VI, 1 de julio de 2005 n $^{\circ} 3672$, www.giustizia-amministrativa.it), el privado es, por tanto, el partner de la Administración concesionaria del servicio que, en todo caso (salvo en las relaciones de valor inferior a los 20.000 euros) tiene que ser elegido a través de un procedimiento selectivo (véase el Art. 1, párrafo 2, del Código de los contratos públicos); de modo que la Administración no está obligada a celebrar contratos ulteriores para la asignación del servicio, que puede adjudicar (conceder) directamente a la sociedad.

La cuestión acerca de la posibilidad que tiene la administración pública de valerse del modelo organizativo de la sociedad mixta para llevar a cabo sus cometidos y para la asignación de servicios públicos de relevancia económica ha sido objeto en los últimos años de una cuidadosa elaboración jurisprudencial tanto en el ámbito comunitario como nacional. En especial, con el parecer del Cons. St., II, 18 de abril de 2007, $n^{\circ} 456$ cit., y con la Sentencia del Pleno $n^{\circ} 1$ del 3 de marzo de 2008, por primera vez se definieron las condiciones para la adjudicación directa de un servicio público a una sociedad, esto es, según emana también de la jurisprudencia más reciente, 1) que exista una norma legal que autorice a la administración para valerse de dicho "instrumento"; 2) que el partner privado se elija por concurso; 3) que la actividad de la sociedad de constitución mixta se ceda, al menos de forma prevalente, a favor de la autoridad pública que haya procedido a la constitución de la misma; 4) que el concurso (único) para la elección del socio y la adjudicación de los servicios defina exactamente el objeto de los propios servicios (ha de tratarse de servicios "determinados"); 5) que la selección de la mejor oferta se compare no sólo con la solidez financiera del ofertante, sino también con la capacidad de desempeñar las prestaciones específicas objeto del contrato; 6) que la relación que se establezca tenga una duración predeterminada.

Para enmarcar de forma exacta el fenómeno en clave eurounitaria, en primer lugar vale la pena hacer referencia a la Resolución sobre los partenariados público-privados y el derecho comunitario de los contratos públicos y de las concesiones del 26 de octubre de 2006 (2006/2043 (INI)), en los que se afirma, entre otras cosas, que "si la primera convocatoria de concurso para la constitución de una empresa mixta ha sido precisa y completa, no es necesaria una convocatoria ulterior" (punto 40), así como, más recientemente, la Comunicación interpretativa de la Comisión Europea del 5 de febrero de 2008, en C (2007) 6661, sobre la aplicación del derecho comunitario de los contratos públicos y de las concesiones a los partenariados público-privados institucionalizados (PPPI).

Dado que el partenariado institucional puede derivar tanto de la constitución de una nueva sociedad mixta como de la participación del privado en una sociedad pública preexistente, la Comunicación afirma de forma preliminar que las normas en materia de contratos y concesiones deben encontrar aplicación tanto en relación con la elección del socio como en la asignación del contrato. Sin embargo, dado que el doble concurso no parece ser concretamente ventajoso (el término original utilizado es "practical"), la Comisión sugiere que el partner privado se elija a través de un concurso que tenga por objeto tanto el contrato o concesión a adjudicar, como la contribución del mismo partner privado en términos operativos y directivos a la sociedad mixta (lo que parece excluir un mero otorgamiento de capitales). La elección del socio privado acompaña en ese punto a la constitución de la sociedad mixta y a la adjudicación del contrato.

De ello se deriva el necesario rigor hacia las llamadas sociedades generalistas, correctamente impuesto por la jurisprudencia ${ }^{6}$ y acogido materialmente por el Código de contratos públicos, allá donde, en el Art. 32, párrafo

5 Sobre la que se remite a M.A. Sandulli, La concessione di servizi, en S. Baccarini-G. Chiné-R. Proietti (Dir.), Codice dell'appalto pubblico, Milán, Giuffrè, 2011.

6 Cons. St., VI, 23 de septiembre de 2008, $\mathrm{n}^{\circ}$ 4603, www.giustizia-amministrativa.it. La jurisprudencia ha destacado correctamente 
3, dispone que las sociedades mixtas no están obligadas a aplicar las disposiciones contenidas en él (por lo que no están obligadas a seguir procedimientos públicos), limitándose a la realización de la obra pública o a la gestión del servicio por las que se han constituido específicamente, si se dan las condiciones indicadas específicamente por la norma. De ello se deriva que la sociedad mixta debe actuar en los límites de la adjudicación inicial y no puede obtener sin concurso misiones ulteriores que no estén ya previstas en la convocatoria original.?

La referida tendencia hacia una rigidez del sistema ha sido ulteriormente desarrollada por el legislador italiano que, en el Art. 3, párrafo 27 de la Ley n 244 del 24 de diciembre de 2007 (Ley de Presupuestos de 2008), ha establecido que "con objeto de tutelar la competencia y el mercado, las administraciones indicadas en el artículo 1, párrafo 2, del Decreto Legislativo $n^{\circ} 165$ del 30 de marzo de 2001 no pueden constituir sociedades cuyo objeto sea la actividad de producción de bienes y servicios NO ESTRICTAMENTE NECESARIOS para la persecución de sus finalidades institucionales, ni asumir o mantener directa o indirectamente participaciones, ni siquiera minoritarias, en dichas sociedades", añadiendo además que "Se admite siempre la constitución de sociedades que produzcan servicios de interés general [debiéndose entender que se prescinde del régimen jurídico bajo el que tiene lugar dicha producción] y la asunción de participaciones en tales sociedades por parte de las administraciones mencionadas en el artículo 1, párrafo 2, del Decreto Legislativo $n^{\circ} 165$ del 30 de marzo de 2001, en el ámbito de los respectivos niveles de competencia".

De este modo, como recientemente se ha puesto de manifiesto en la doctrina ${ }^{8}$, al límite tradicional de la prohibición de desarrollar en forma societaria actividades institucionales del ente (salvos los casos expresamente permitidos por la ley), se añadía el de que las actividades de producción de bienes y servicios no se pueden gestionar en forma societaria si no son "estrictamente necesarias" para el logro de las finalidades institucionales del partner público. La escasa claridad de la norma ha provocado una interpretación restrictiva que excluye las actividades de mero soporte, en general instrumentales para los diversos tipos de actividades, para admitir solo las estrictamente pertinentes para los fines institucionales del ente.

Es expresión de ello la Sentencia $n^{\circ} 10$ de 2011, con la cual, invocando dicho principio, la Sesión plenaria del Consejo de Estado, partiendo de la premisa de que las universidades, en el ámbito de su propia autonomía organizativa y financiera, pueden dar vida a sociedades solo para perseguir sus propios fines institucionales, y no para suministrar servicios disputables en el mercado, recientemente, como es sabido, ha declarado la ilegitimidad de los actos con los que la IUAV de Venecia había previsto constituir una sociedad comercial de engineering, con evidentes fines de lucro, sin establecer límites puntuales que garantizasen la estricta instrumentalidad con respecto a los fines institucionales de la propia universidad. Por lo tanto, por un lado, parece que la sentencia -restrictivamente- pretende una relación de instrumentalidad/continencia entre la sociedad y el ente público no solo en el objeto, sino también en los fines (excluyendo en términos generales la persecución de fines lucrativos por parte de la sociedad) y, por otro lado, que acoge una solución de mayor apertura, permitiendo la constitución de sujetos con fines empresariales-lucrativos, aunque necesariamente destinando los beneficios a finalidades de interés público9.

Además, tiene particular importancia la excepción de la prohibición para los servicios de interés general, que por tanto se pueden desempeñar normalmente en forma societaria. A su vez, refiriéndose específicamente a las administraciones regionales y locales, el Art. 13 del D.L. ${ }^{\circ} 223$ de 4 de julio de 2006, convertido en la Ley 248/2006, dejando expresamente fuera de su propio ámbito el particularísimo sector de la gestión de los servicios públicos locales (a los que volveremos enseguida), había aclarado en términos manifiestamente categóricos que "con objeto de evitar alteraciones o distorsiones de la competencia y del mercado y asegurar la paridad de los operadores,

al respecto que "La respuesta a la cuestión de si los contratos públicos se pueden adjudicar a sociedades mixtas de forma directa, o si hace falta seguir procedimientos de concurrencia pública, se debe diferenciar haciendo necesaria la distinción entre la hipótesis de constitución de una sociedad mixta para una misión específica, sobre la base de un concurso que tenga por objeto tanto la elección del socio como la asignación de la misión específica, y la hipótesis de que se quieran adjudicar contratos ulteriores a una sociedad mixta ya constituida. En relación con el primer caso, tras una evolución compleja, la jurisprudencia nacional (véanse por último Cons. St., ad. plen., 3 de marzo 2008, $n^{\circ} 1$; sec. V, 23 de octubre de 2007, $n^{\circ}$ 5587; sec. Il, 18 de abril de 2007, nº 456/07) y comunitaria (véase Corte Giust. CE, sec. I, 11 de enero de 2005, nº C-26/03) ha llegado a la conclusión de que, respetando límites precisos, es suficiente un concurso único. En cambio, en el segundo caso hace falta un concurso para la adjudicación de los contratos ulteriores y sucesivas con respecto a la misión original”: véase Cons. St., V, 13 de febrero de $2009, \mathrm{n}^{\circ} 824$.

7 Según el tenor de la sentencia citada, "No es admisible una sociedad mixta <<abierta >>0 $<<$ generalista $>>$ a la que adjudicar de forma directa, tras su constitución, un número indefinido de contratos o de servicios públicos". Con la siguiente Sentencia sec. VI, 16 de marzo 2009 , $\mathrm{n}^{\circ}$ 1555, el Consejo de Estado, aún confirmando los antedichos principios, ha considerado la admisibilidad de la previsión, en la lex specialis para la licitación única, de la posible adjudicación de servicios ulteriores, añadidos y complementarios a la principal, destacando que "teniendo en cuenta la duración de la relación (nueve años en el caso en cuestión, pero es muy arduo plantear la hipótesis de un interés de la administración en recurrir al módulo organizativo examinado por periodos muy limitados bajo el perfil temporal) y la complejidad inherente a las tareas asignadas parece congruente que se pueda prever (evidentemente en medida reducida con respecto a las tareas necesariamente asignadas) la posibilidad de que se asignen otras, sin que por ello solo se convierta en la-inadmisible-forma de de una sociedad "generalista" o se trasforme el concepto de "determinación del servicio" en el de "determinabilidad" del mismo".

8 A. Lolli, Le società miste, en F. Mastragostino (Dir.), La collaborazione, cit., 311.

9 Sobre las perplejidades suscitadas por esta solución, en relación con el sistema de códigos, véase. F. Goisis, La strumentalità pubblicistica delle società a partecipazione pubblica: profili critici di diritto nazionale e comunitario e implicazioni di riparto di giurisdizione, en Dir. proc. amm. 2011,1364 ss. 
las sociedades de capital enteramente público o mixto, constituidas o participadas por las administraciones públicas regionales y locales PARA LA PRODUCCIÓN DE BIENES Y SERVICIOS INSTRUMENTALES para la actividad de dichas entidades, en función de su actividad [con exclusión de los servicios públicos locales], así como EN LOS [ÚNICOS] CASOS QUE PERMITA LA LEY, para el desempeño externalizado de funciones administrativas de su competencia, deben operar exclusivamente con las entidades constituyentes o participantes o adjudicatarias, no pueden realizar prestaciones a favor de otros sujetos públicos o privados, ni mediante adjudicación directa ni por concurso, y no pueden participar en otras sociedades o entidades". ${ }^{10}$

Según ha puesto también claramente de manifiesto la jurisprudencia (Consiglio di Stato, Sec. V, nº 1037 y 7080 de 2010), las razones por las que la sociedad instrumental representa una distorsión del libre juego de la competencia consisten realmente en el riesgo de que se creen situaciones particulares de privilegio para algunas empresas cuando estas últimas, sustancialmente, se aprovechen de una ayuda estatal, es decir, una provisión económica pública destinada a disminuir o cubrir los costes: es un privilegio que no se concreta necesariamente en la contribución o el subsidio directo o en beneficios fiscales o contributivos, sino también garantizando una posición en el mercado ventajosa con respecto a otras empresas debido a la obtención segura de contratos cuyos ingresos sean capaces de cubrir, si no la totalidad, sí la mayor parte de los gastos generales: en resumen: un mínimo garantizado suficiente para mantener el aparato empresarial. En una situación así, cualquier obtención ulterior de contratos podrá producirse ofreciendo en el mercado condiciones competitivas, dado que la empresa no tendrá que imputar al nuevo contrato también la parte de costes generales ya cubierta, sino solo el coste directo de producción. Sustancialmente, los contratos ulteriores se tornan más que marginales y permiten realizar un beneficio mayor con respecto a la economía ordinaria de las empresas del sector, o bien ofrecer al mercado precios antinaturalmente más bajos porque no están gravados con la amortización de los gastos generales. En particular, se ha subrayado que, tanto en un caso como en el otro, el mecanismo del mínimo garantizado altera la par condicio de las empresas de forma aún más grave, porque también repercute en el mercado de los contratos privados. De hecho, la empresa beneficiaria de este tipo de mínimo garantizado es competitiva no solo en los concursos públicos, sino también con respecto a los contratistas privados dado que, en definitiva, un sistema así se vuelve mucho más peligroso y distorsionador que una simple elusión del sistema de concursos.

En relación con el marco de la instrumentalidad, la calificación diferencial entre actividades instrumentales y gestión de servicios públicos destinados a la aplicación del citado Art. 13 del D.L. nº 223 de 2006 se debe referir ya no al objeto de la licitación, sino al objeto social de las empresas participantes, dado que la prohibición de suministrar prestaciones a terceras entidades por parte de las sociedades públicas instrumentales a las administraciones regionales o locales, que ejercen actividad administrativa de una forma privatista, tiende a separar las dos esferas de actividad para evitar que un sujeto que desempeñe una actividad administrativa ejerza al mismo tiempo una actividad de empresa, beneficiándose de unos privilegios de los que puede gozar como administración pública (Cons. Stato, sec. V, 22 de marzo $2010 \mathrm{n}^{\circ}$ 1651).

Se reitera que el límite concierne únicamente a las sociedades constituidas o participadas por las administraciones locales para la producción de servicios instrumentales a su actividad y, por tanto, en función y soporte de la misma, y no a las sociedades, tanto las de capital únicamente público como las mixtas, constituidas para el desarrollo de los servicios públicos locales (Cons. Stato, ses. plen., $\mathrm{n}^{\circ} 17$ de 2011)

De este modo, la prohibición encuentra aplicación pacífica para las sociedades llamadas de segundo nivel, es decir, constituidas y participadas por sociedades instrumentales de las administraciones públicas que las han constituido y por las que son íntegra o parcialmente participadas, dado que, si se piensa de otro modo, la prohibición de desempeñar actividades diferentes de las permitidas expresamente a los sujetos que gozan del beneficio del mínimo garantizado se eludiría indirectamente. Este también es el caso a la luz de la prohibición ulterior, impuesta por el Art. 13, párrafo 1, a las mismas sociedades instrumentales, de participar en otras sociedades o entidades con sede en el territorio nacional. La antinomia aparente con la norma (Art. 13, párrafo 3), que permite a las sociedades instrumentales separar las actividades no permitidas confiándolas a una sociedad separada, se ha considerado "superable interpretando la norma que prevé la separación en el único sentido lógicamente coherente con la obligación de cese, es decir, para promover una operación que, en la creación del organismo destinado a gestionar las actividades transferidas, no conlleve la intervención financiera decisiva de la entidad instrumental. En otras palabras, la separación de las actividades por parte de las sociedades instrumentales mediante la constitución de una sociedad separada interrumpe la prohibición indicada en el Art. 13 si la nueva sociedad está efectivamente "separada", es decir,

10 Luego, el mismo artículo ha excluido de esta última prohibición participativa a las sociedades que desempeñan actividades de intermediación financiera prevista por el texto único del que trata el DecretoLegislativo n 385 del 1 de septiembre de 1993.

11 F. Foggia, Condizioni per l'accesso paritetico al mercato dei servizi delle società miste e delle società cd. "di terza generazione" (Cons. Stato, Ad. Plen., 4 agosto 2011, n. 17), in Riv. nel diritto, 2011, 1504. 
es autónoma e independiente con respecto a la sociedad instrumental". A este marco normativo pertenece el Art. 14, párrafo 32, del D.L. $n^{\circ} 78$ de 2010, enmendado por la Ley $n^{\circ} 133$ de 2010, el cual ha establecido que, sin perjuicio del arriba citado Art. 27, párrafo 3, de la Ley financiera de 2008 (y, por tanto, como mejor se dirá infra, parecería que establece la excepción de las sociedades asignatarias de servicios públicos locales, que entrarían, en su caso, en el ámbito de los servicios de interés general), los municipios con menos de 30.000 habitantes no pueden constituir sociedades y deben liquidar las sociedades ya constituidas o ceder sus participaciones al 31 de diciembre de 2012, excepto las sociedades consideradas cumplidoras; se excluyen también las sociedades constituidas por varios municipios cuya población total supere los 30.000 habitantes. Los municipios entre 30.000 y 50.000 habitantes pueden poseer la participación en una única sociedad y, al 31 de diciembre de 2011, debían en todo caso liquidar las otras sociedades.

\section{LAS SOCIEDADES MIXTAS PARA LA GESTIÓN DE LOS SERVICIOS PÚBLICOS LOCALES}

Las mayores dificultades reconstructivas se refieren, entre otras cosas, como es bien sabido, a la disciplina de la gestión de los servicios públicos locales, reescrita y modificada repetidamente en los últimos años, hasta las últimas reformas presupuestarias de 2011 y al D.L. $\mathrm{n}^{\circ} 1$ sobre las liberalizaciones de 2012. La materia se caracteriza cada vez más por ese dinamismo normativo que, sobre todo a partir de 2008, se ha convertido en un dato constante, ulteriormente acelerado en estos últimos meses por el resultado del referéndum que tuvo lugar el 12 y 13 de junio de $2011^{12}$ y por la repetidas "reformas" anticrisis.

El punto de partida de la política reformista se constituye, como es sabido, por el Art. 23 bis del D.L. $n^{\circ} 112$ del 25 de junio de 2008, convertido en la Ley $\mathrm{n}^{\circ} 133$ del 6 de agosto de 2008 y sus modificaciones sucesivas [que tuvieron lugar en 2009 mediante el Art. 15 del D.L. $n^{\circ} 135$ del 25 de septiembre de 2009 (llamado Decreto Ronchi o salva-infracciones), convertido en la Ley $n^{\circ} 166$ del 20 de noviembre de 2009], así como por el reglamento de actuación aprobado con D.P.R. $n^{\circ} 168$ del 7 de septiembre de 2010. La nueva norma, aplicable a todos los servicios públicos locales, con prevalencia en las "disciplinas sectoriales... incompatibles", salvo las relacionadas con los cuatro llamados "sectores excluidos" (distribución de gas natural; distribución de energía eléctrica; gestión de las farmacias municipales; transporte ferroviario regional) estaba destinada (entre otras cosas) a permitir la más amplia difusión de los principios de competencia, libertad de establecimiento y libre prestación se los servicios para todos "los operadores económicos interesados en la gestión de servicios públicos de interés general en ámbito local", favoreciendo la gestión de los servicios públicos locales de relevancia económica por parte de sujetos elegidos tras licitación pública, con la consiguiente limitación de los casos de adjudicación directa de la gestión, legitimando la gestión "in house" solo en presencia de situaciones totalmente excepcionales que "no permiten recurrir al mercado de forma útil y eficaz".

Se recuerda que el Art. 15 de la citada Ley 166 de 2009, interviniendo en la disciplina de los servicios locales rediseñada por el citado Art. 23 bis, había dado lugar a un ulterior y radical endurecimiento para con las adjudicaciones directas. El reglamento de actuación del Art. 23 bis de la Ley 133/2008 había definido las modalidades de concreción de la elección, remitida a una resolución marco destinada a ilustrar, para los sectores sustraídos a la liberalización, los fracasos del sistema de competencia y los beneficios del mantenimiento de un régimen de exclusividad del servicio para la estabilización, el desarrollo y la equidad dentro de la comunidad local. El mismo reglamento fijó el umbral más allá del cual el mantenimiento de la exclusividad estaba supeditado al parecer de la Autoridad nacional Antitrust, indicándola en los servicios de valor superior a los 200.000 euros/año (independientemente de su duración y, por tanto, del valor total del contrato).

Sobre estas bases, aunque con un perfil inconstante, se ha movido y se está desarrollando la legislación posterior, siguiendo el empuje político hacia una liberalización progresiva de los servicios y de las actividades que tradicionalmente se atribuyen a la mano pública.

Las normas anteriormente mencionadas, tras una criba sustancialmente positiva de legitimidad constitucional por parte de la conocida Sentencia ${ }^{\circ} 35$ de 2010, se han derogado por efecto de un controvertido referéndum popular de junio de 2011, con la consiguiente aplicación inmediata de la normativa comunitaria en el ordenamiento interno. Por lo tanto, sin perjuicio de la obligación de cumplir el procedimiento de concurrencia público para la adjudicación del servicio a terceros o para la elección del partner privado de las sociedades mixtas, la gestión "in house", aun conservando carácter de excepcionalidad (como ya destacó la Sesión plenaria del Consejo de Estado en la conocida Sentencia $n^{\circ} 1$ de 2008) generalmente se permitía a favor de sociedades de capital íntegramente

12 Véase para todos la reconstrucción de C. Volpe, Appalti pubblici e servizi pubblici. Dall’Art. 23-bis al decreto legge manovra di agosto 2011 attraverso il referendum: l'attuale quadro normativo, en www.giustamm.it, n 10-2011; así como las reflexiones de A. Vigneri, La disciplina dei servizi pubblici locali nell'Art. 4 della legge 148/2011. Brevi considerazioni sul nuovo quadro normativo, (en la página: http://www.astrid-online.it/ Riforma-de2/Studi-e-ri/VIGNERI-_spl_15-10-11.pdf 
público, previa comprobación de la existencia del control análogo y del carácter prevalente de la actividad, y sin los varios "corsés" impuestos por el Art. 23-bis.

Como ya destacó el Tribunal Constitucional con la Sentencia $n^{\circ} 325 / 2010$, la normativa comunitaria admite, de hecho, la gestión directa de los servicios públicos en caso de que el Estado nacional considere que la aplicación de las normas de competencia (y, por tanto, también de la norma que establece la necesidad de la adjudicación a terceros mediante una licitación pública) obstaculize, en derecho o hecho, la "misión especial" de la entidad pública (Art. 106 del Tratado sobre el funcionamiento de la Unión Europea; Sentencias de Tribunal de Justicia UE 11 de enero de 2005, C-26/03, Stadt Halle, apartados 48 y 4925, y 10 de septiembre de 2009, C-573/07, Sea s.r.l. 26). En dicha hipótesis, el ordenamiento comunitario, respetuoso de la amplia esfera discrecional atribuida a los Estados miembros, se reserva solo decidir si la decisión del Estado es fruto de un "error manifiesto".

En relación con las sociedades mixtas, se recuerda que el modelo de la llamada licitación con doble objeto (que concierne tanto a la calidad de socio como a la gestión del servicio), en la que la sociedad se constituye para una específica finalidad sobre la base de una licitación que tiene por objeto la elección del socio y la adjudicación de la finalidad específica (hipótesis que hace de contrapeso para aquella diferente y no permitida en la que contratos ulteriores se quieren adjudicar a una sociedad mixta ya constituida), previsto en Italia por el citado D.L. 135 de 2009, había sido expresamente admitido por la Comunicación interpretativa de la Comisión Europea el 5 de febrero de 2008 "sobre la aplicación del derecho comunitario de las contratos públicas y de las concesiones a los partenariados público-privados institucionalizados (PPPI)" y, posteriormente, confirmado por el Tribunal de Justicia CE (véase la Sentencia sec. III, 15 de octubre de 2009, en C-196/08).

Por lo tanto, en el periodo inmediatamente posterior al referéndum valía la norma de la admisibilidad de la adjudicación a una sociedad mixta, previa licitación con doble objeto y sin ninguna previsión de porcentajes de participación (pública o privada).

\section{SIGUE: LAS REFORMAS DE 2011 Y EL D.L. SOBRE LIBERALIZACIONES DEL 20 DE ENERO DE 2012}

Dicha fase de interregno ha tenido, además, una duración muy breve y, en la reforma financiera del 15 de agosto, Ilamada "Ulteriores medidas urgentes para la estabilización financiera y para el desarrollo", el legislador ha vuelto a intervenir puntualmente en esta delicada materia ${ }^{13}$.

Se trataba, como es sabido, de la segunda reforma económica un mes después de la primera, y representaba la respuesta del Gobierno a la situación excepcional de crisis internacional y de inestabilidad de los mercados para garantizar la estabilidad del país y respetar los compromisos asumidos en la Unión Europea, así como aplicar medidas destinadas a fomentar el desarrollo y la competitividad del país y apoyar el empleo.

Bajo esta óptica, mientras que el Art. 23-bis del D.L. $n^{\circ} 112 / 2008$, convertido con modificaciones en la Ley $n^{\circ}$ 133/2008 y modificaciones e integraciones posteriores, se centraba sobre todo en las privatizaciones, el Art. 4 del D.L. n 138/2011, convertido con modificaciones en la Ley n 148/2011, bajo el título “Adecuación de la disciplina de los servicios públicos locales al referéndum popular y a la normativa en la Unión Europea", por tanto, ha dado una vuelta de tuerca decisiva hacia las liberalizaciones ${ }^{14}$.

Se afirma al respecto y de forma significativa en el íncipit del artículo, que las entidades locales, en cumplimiento de los principios de competencia, libertad de establecimiento y libre prestación de los servicios, así como, según la modificación introducida por el D.L. sobre liberalizaciones, "después de haber identificado los contenidos específicos de las obligaciones de servicio público universal", deben verificar la factibilidad de una gestión de la competencia de los servicios públicos locales de relevancia económica, definidos más simplemente también como «servicios públicos locales», liberalizando todas las actividades económicas de forma compatible con las características de universalidad y accesibilidad del servicio y limitando, en los otros casos, la asignación de derechos de exclusividad a las hipótesis en las que, sobre la base de un análisis de mercado, la libre iniciativa económica privada no resulte apta para garantizar un servicio que responda a las necesidades de la comunidad. Por tanto, se admite la atribución de derechos de exclusividad solo de forma residual, en caso de que la liberalización no logre satisfacer las necesidades de la comunidad (Art. 4, párrafos 1, 2 y 4, del D.L. n 138/2011).

13 Sobre las novedades introducidas con el D.L. $\mathrm{n}^{\circ} 138$ de 2011, véase: A. Avino, Quale destino per le società miste alla luce dell’Art. 4 del D. L. 138/2011? en www.dirittodeiservizipubblici.it; E. Furno, La never ending story dei servizi pubblici locali di rilevanza economica tra aspirazioni concorrenziali ed esigenze sociali: linee di tendenza e problematiche aperte alla luce del D.L. n. 138/2011, en www.giustamm.it, $n^{\circ}$ 9-2011; G. Guzzo, I spl di rilevanza economica dopo il restyling del D.L. n. 138/2011: "nuove" regole e vecchie questioni, en www.lexitalia.it, $n^{\circ}$ 7-8/2011; M. Lombardo, La governance delle società a controllo pubblico: riflessioni a margine della nuova disciplina normativa dei servizi pubblici locali, en www.dirittodeiservizipubblici.it; I. Rizzo, I servizi pubblici dopo il D.L. 138/2011, en Urbanistica e appalti, 2011, 1398; C. Volpe, Appalti pubblici e servizi pubblici. Dall'Art. 23-bis al decreto legge manovra di agosto 2011 attraverso il referendum: l'attuale quadro normativo, en www. giustamm.it, $\mathrm{n}^{\circ} 10-2011$.

14 Véase para todos de nuevo C. Volpe, Servizi pubblici locali e legge di stabilità, en www.federalis-mi.it 
En este contexto tiene especial significado la previsión de un mecanismo premiador en el plano financiero, ante el pacto de estabilidad, para las entidades que procedan a liberalizar los servicios públicos.

El Art. 3 del D.L. n 138/2011, tras prescribir en el párrafo 1 que "Municipios, Provincias, Regiones y Estado, en un plazo de un año a partir de la fecha de entrada en vigor de la ley de conversión del presente decreto, adaptan sus respectivos ordenamientos al principio según el cual la iniciativa y la actividad económica privada son libres y está permitido todo lo que no está expresamente prohibido por la ley" en los únicos casos indicados, establece, en el párrafo 4, que "La adaptación de Municipios, Provincias y Regiones a la obligación indicada en el párrafo 1 constituye elemento de valoración del cumplimiento de las antedichas" entidades según el Art. 20, párrafo 3, del D.L. n 98/2011, convertido en la Ley n $n^{\circ} 111 / 2011$, para la adaptación a los objetivos de las finanzas públicas.

Del mismo modo, en relación con el transporte público local, se considera criterio de cumplimiento -para la distribución a partir de 2012 del 50 por ciento de los recursos del fondo para la financiación del transporte público local, incluso del ferroviario, en las regiones con estatuto ordinario, establecido en el Ministerio de Economía y Finanzas- "la atribución de la gestión de los servicios de transporte con procedimiento de pública concurrencia" (Art. 1, párrafo 13, del D.L. n 138).

La nueva normativa retomaba algunos contenidos del Art. 23-bis y, oportunamente, elevaba al rango de fuente primaria, con algunas modificaciones, muchas de las normas contenidas en el reglamento aprobado con el D.P.R. $n^{\circ} 168 / 2010$, con dos diferencias sustanciales:

a) inaplicabilidad al servicio de aguas integrado (con la única excepción de las disposiciones en materia de incompatibilidad; párrafos del 19 al 27), además de a los sectores habituales excluidos, como el servicio de distribución de gas natural y el de energía eléctrica, el servicio de transporte ferroviario y la gestión de las farmacias municipales (párrafo 34);

b) como excepción al procedimiento de competición pública, permitía la gestión "in house" a sociedades con capital íntegramente público y en presencia de los requisitos requeridos por el ordenamiento europeo solo si el valor económico del servicio objeto de la adjudicación era igual o inferior al importe total de 900.000 euros anuales (cifra reducida a 200.000 euros por el D.L. sobre liberalizaciones); sin la previsión de límites o condiciones ulteriores (párrafo 13). Así que, por debajo de dicho umbral, las entidades eran libres de gestionar un servicio de relevancia económica en régimen de autoproducción.

Sin embargo, la reforma reintroducía para las sociedades "in house" adjudicatarias directas de la gestión de servicios públicos locales la sujeción al pacto de estabilidad interno (según las modalidades definidas por el decreto ministerial previsto por el Art. 18, párrafo 2-bis del D.L. 112 de 2008, convertido en la Ley ${ }^{\circ} 133$, y modificaciones e integraciones posteriores ${ }^{15}$ ) bajo la vigilancia de las entidades participantes; además de la obligación, común a todas las sociedades mixtas, de cumplir con los procedimientos públicos para la adquisición de bienes y servicios para la contratación del personal (párrafos 15 y 17).

En el centro de la reforma se sitúa la antedicha verificación preliminar, por parte de las mismas entidades, de la "factibilidad de una gestión de competencia de los servicios públicos locales de relevancia económica... liberalizando todas las actividades económicas" con limitación de los derechos de exclusividad "a las hipótesis en las que, sobre la base de un análisis de mercado, la libre iniciativa económica privada no resulte apta para garantizar un servicio que responda a las necesidades de la comunidad": verificación que se ha de llevar a cabo por medio de una resolución marco que se ha de aplicar periódicamente y, en cualquier caso, antes de proceder al otorgamiento y la renovación de la gestión de los servicios.

En el texto actualmente en vigor (tras el D.L. sobre liberalizaciones $n^{\circ} 1$ de 2012 , convertido en la Ley $n^{\circ} 27$ de 2012), se lee que la resolución se debe adoptar previo parecer obligatorio de la Autoridad, que "se pronuncia en un plazo de sesenta días, sobre la base de la instrucción llevada a cabo por el gobierno local del ámbito o sector o, en su ausencia, por la entidad local, en relación con la existencia de razones idóneas y bastantes para la atribución de derechos de exclusividad y la corrección de la elección eventual para proceder con la adjudicación mediante licitación de una pluralidad de servicios públicos locales". La misma norma precisa que tanto la resolución como el parecer se deben hacer públicos en la página web, si existe, y posteriormente a través de las modalidades idóneas, y que el envío de la verificación y del correspondiente esquema de resolución marco a la Autoridad se debe "realizar en los

15 Sobre la base del D.L. sobre liberalizaciones, aprobado por el Consejo de Ministros el 20 de enero pasado, en el periodo hasta la adopción de dicho decreto, y salvos los compromisos asumidos en convenios, contratos de servicio o de programas ya suscritos en la fecha de entrada en vigor del presente decreto con referencia a la aplicación de los planes sectoriales, las sociedades in house adjudicatarias pueden contraer hipotecas para la realización de inversiones con el límite de que el importe de los intereses de cada cuota anual de amortización que grave en el balance de la empresa, sumado al importe de los intereses de las hipotecas previamente suscritas, no supere el 25 por ciento de los ingresos efectivos de la empresa estimados sobre la base del balance del ejercicio precedente. 
doce meses posteriores a la entrada en vigor del presente decreto y después periódicamente según los ordenamientos respectivos de las entidades locales", y que la resolución, se debe "adoptar, en todo caso, antes de proceder a la adjudicación y a la renovación de la gestión de los servicios, en un plazo de treinta días desde el parecer de la Autoridad garante de la competencia y del mercado. En ausencia de la resolución, la entidad local no puede proceder con la atribución de los derechos de exclusividad según el presente artículo". Por lo tanto, no se retoma la referencia al silencio positivo, sino que, sobre todo, no se fija un plazo para expresar el parecer y no se regulan las consecuencias de su falta de aplicación.

En todo caso, como se ha adelantado, la ley empuja de esta forma prioritariamente hacia la realización de la competencia EN EL mercado, es decir, de un proceso de liberalización de las actividades económicas, que tiene como contrapunto la eliminación de los derechos de exclusividad, que se han de atribuir, aún siempre en el respeto de la competencia POR el mercado (y, por tanto, previo procedimiento competitivo público en cumplimiento de los principios del Tratado sobre el Funcionamiento de la Unión Europea y de los principios generales sobre los contratos públicos ${ }^{16}$ ), solo en vía residual, en caso de que una liberalización no logre satisfacer las necesidades de la comunidad que, en cambio, obtiene beneficios del mantenimiento de un régimen de exclusividad ${ }^{17}$.

La reforma de 2011 impone a las entidades locales que definan, donde sea preciso, las obligaciones de servicio público necesarias para asegurar a los usuarios el suministro de servicios públicos que tengan por objeto la producción de bienes y actividades destinadas a realizar fines sociales y a promover el desarrollo económico y civil de las comunidades locales, previendo las eventuales compensaciones económicas a las empresas que gestionen dichos servicios, teniendo en cuenta los ingresos derivados de las tarifas y en los límites de la disponibilidad presupuestaria destinada a dicho fin.

La atribución de derechos de exclusividad a una empresa encargada de la gestión de servicios públicos locales conlleva para los terceros la prohibición de producir los mismos servicios para uso propio, y los gestores de servicios públicos locales, en caso de que deseen desempeñar actividades en mercados diferentes en los que sean titulares de derechos de exclusividad, deben realizar una separación societaria.

Las sociedades de capital íntegramente público pueden participar en los procedimientos competitivos públicos, siempre y cuando no haya prohibiciones específicas previstas por la ley, sin perjuicio del principio de reciprocidad para las empresas extranjeras que no pertenezcan a Estados miembros de la Unión Europea en cuanto a la posibilidad de admisión en los procedimientos competitivos públicos para la adjudicación de servicios públicos locales.

El anuncio de los procedimientos competitivos públicos para la adjudicación de los servicios públicos locales se rige por normas especiales, destinadas a garantizar el mejor respeto de la situación de la competencia en los mercados interesados. El D.L. sobre liberalizaciones, más específicamente, ha establecido el compromiso del sujeto gestor de obtener economías de gestión en relación con la duración total programada de la adjudicación, previendo, entre los elementos de valoración de la oferta, la medida de estas economías y su finalidad para la reducción de las tarifas que se apliquen a los usuarios y a la financiación de instrumentos de apoyo vinculados a procesos de aumento de la eficiencia relacionados con el personal. Además, se han dictado prescripciones específicas para las licitaciones que conciernen a la adjudicación del servicio a una sociedad mixta previa "licitación con doble objeto", con la salvedad de que el socio privado seleccionado debe poseer una participación no inferior al 40 por ciento y debe desempeñar las "tareas operativas específicas" ligadas a la gestión del servicio durante toda la vigencia del servicio mismo y que, donde esto no ocurra, se debe proceder a una nueva adjudicación.

Como garantía de correcta gestión, el legislador confía la vigilancia al órgano de revisión del ente local participante (y adjudicador) la verificación de que se respeta el contrato de servicio, y prescribe la separación entre las funciones de regulación y las de gestión, fijando una serie de incompatibilidades y prohibiciones para los nombramientos y los encargos que se hagan con posterioridad a la fecha de entrada en vigor del decreto. Finalmente, se precisa que, quedando a salvo la propiedad pública de las redes, su gestión se puede encargar a sujetos privados.

16 El párrafo 8 establece, en especial, que en caso de que, tras la verificación prevista por el párrafo 1, la entidad quiera proceder con la atribución de derechos de exclusividad, el otorgamiento de la gestión de servicios públicos locales se realiza a favor de empresarios o sociedades constituidas de cualquier forma, identificadas mediante procedimientos competitivos públicos, en cumplimiento de los principios del Tratado sobre el funcionamiento de la Unión Europea y de los principios generales correspondientes a los contratos públicos y, en especial, de los principios de economicidad, imparcialidad y transparencia, publicidad adecuada, no discriminación, igualdad de trato, reconocimiento mutuo y proporcionalidad. Los mismos procedimientos se han anunciado en cumplimiento de los estándares cualitativos, cuantitativos, medioambientales, de distribución ecuánime en el territorio y de seguridad definidos por la ley, si existe, por la autoridad de sector competente o, a falta de ésta, por las entidades adjudicadoras.

17 C. Volpe, op. ult. cit. 
Un perfil particularmente delicado lo constituye, evidentemente, el régimen transitorio de los encargos actualmente en curso para el paso gradual al nuevo régimen y para la progresiva apertura del mercado a favor de los operadores privados, cuya disciplina está sujeta a continuos ajustes ${ }^{18}$.

La Ley 183 de 2011, entre otras cosas, ha desvirtuado la prohibición de extraterritorialidad para las sociedades mixtas siempre que estén constituidas en el sentido del párrafo 12 del citado Art. 4 del D.L. n 138/2011, de modo tal que la disciplina de la gestión de los servicios públicos locales se diferencia nuevamente -mientras que antes se había equiparado- de la que expone el mencionado Art. 13 del D.L. n 223 del 4 de julio de 2006, convertido, con modificaciones, en la Ley $n^{\circ} 248$ del 4 de agosto de 2006, en la parte en la que prevé que las sociedades de capital enteramente público o mixto, constituidas o participadas por las administraciones públicas regionales y locales para la producción de servicios destinados a las actividades desempeñadas por ellas, deben operar exclusivamente con las entidades constituyentes, participantes o adjudicadoras y no pueden desempeñar prestaciones (obras, servicios y suministros) a favor de otros sujetos públicos o privados, ni participar en otras sociedades o entidades.

Por otro lado, la nueva disciplina, como se ha visto anteriormente, ha planteado fuertes interrogantes sobre los que también ha intervenido significativamente la Autoridad Antitrust con la pertinente notificación al Parlamento.

En el ámbito de las intervenciones destinadas a reaccionar ante la gravísima crisis económico-financiera que sufre nuestro país, tratando de conseguir una apertura más efectiva a la competencia, el legislador también ha intervenido de nuevo en la disciplina de qua de forma significativa.

Me refiero sobre todo al Art. 9, párrafo 2 de la Ley nº 183 del 12 de noviembre de 2011 (Ley de estabilidad 2012) ${ }^{19}$ que, utilizando la técnica de la enmienda, o modificando el texto del citado Art. 4 del D.L. n 138/2011, se ha destinado específicamente a superar alguno de los aspectos críticos encontrados con respecto a este último artículo y ha introducido novedades significativas en el sector de las sociedades públicas. En especial, las finalidades perseguidas por la nueva reforma económica, enumeradas expresamente en el Art. 9, párrafo 2, primera parte, de la Ley $n^{\circ}$ 183/2011, consisten en:

— "realizar un sistema liberalizado de los servicios públicos locales de relevancia económica mediante la competencia plena en el mercado";

— "perseguir los objetivos de liberalización y privatización de los mismos servicios" según lo previsto por el Art. 4 del D.L. n 138/2011;

18 Según se ha observado agudamente (C. Volpe, op. ult. cit.), la norma indicada en el párrafo 32 también plantea un problema de fondo delicado. De hecho, el antedicho párrafo establece, al principio, que permanece válido lo previsto en el Art. 14, párrafo 32, del D.L. $\mathrm{n}^{\circ}$ 78/2010, convertido, con modificaciones, en la Ley $n^{\circ}$ 122/2010 y modificaciones posteriores. Por lo tanto, surge la pregunta de si el citado Art. 14, párrafo 32, se aplica a los servicios públicos locales. Si la respuesta fuera afirmativa decaería en su mayor parte la operatividad de la reforma, dado que el recurso a la constitución de sociedades mixtas y sociedades “in house" -en los casos y con los límites permitidos por los párrafos 12 y 13 del mencionado Art. 4 del D.L. $n^{\circ}$ 138/2011- se reduciría enormemente. Los municipios con menos de 30.000 habitantes no pueden constituir sociedades y, al 31 de diciembre de 2012 a más tardar, deben liquidar las sociedades ya constituidas o ceder sus participaciones, con la exclusión solo de las sociedades consideradas cumplidoras; representan una excepción las sociedades constituidas por más municipios cuya población total supere los 30.000 habitantes. Los municipios de entre 30.000 y 50.000 habitantes pueden ostentar la participación de una única sociedad y, en todo caso, a 31 de diciembre de 2011 tenían que liquidar las otras sociedades. Sin embargo, el Art. 14, párrafo 32, del D.L. $\mathrm{n}^{\circ} 78 / 2010$, convertido, con modificaciones, en la Ley n 122/2010, a su vez comienza con el inciso: "Sin perjuicio de lo previsto por el Art. 3 , párrafos 27,28 y 29, de la Ley $n^{\circ} 244$ del 24 de diciembre de 2007 ". Ahora bien, como se ha recordado arriba, mientras la primera parte de dicho párrafo 27 prohíbe a las administraciones públicas constituir "sociedades que tengan por objeto actividades de producción de bienes y servicios no estrictamente necesarias para el logro de las propias finalidades institucionales" y "adquirir o mantener directamente participaciones, incluso minoritarias, en dichas sociedades", la segunda parte prevé que "Se admite siempre la constitución de sociedades que produzcan servicios de interés general" (categoría en la que evidentemente entran los servicios públicos locales). Esta última posibilidad, que se mantiene expresamente salva en el tenor inicial del citado Art. 14, párrafo 32, y la equiparación entre servicios de interés general (noción de origen comunitario) y servicios públicos debería, por tanto, excluir la aplicabilidad de la disposición introducida para los servicios públicos locales por el Art. 4 del D.L. $n^{\circ}$ 138/2011. Por lo tanto, como ya sugirieron los primeros comentaristas, se debe concluir que la disciplina que trata el citado Art. 14, párrafo 32, se aplica a los servicios públicos locales solo en lo que respecta al régimen transitorio establecido por el citado Art. 4 del D.L. $n^{\circ} 138 / 2011$. En particular, si se produce el cese de la adjudicación en las fechas indicadas por el citado Art. 4, párrafo 32, del D.L. n 138/2011, a la sociedad (ya no adjudicataria) y al municipio se les aplica lo dispuesto por el citado Art. 14, párrafo 23; en caso contrario, las adjudicaciones cesan en la fecha prevista en el contrato de servicio y no se aplica el Art. 14, párrafo 32. Según una opinión distinta -es decir, considerando que el citado Art. 14, párrafo 32, también se aplica a los servicios públicos locales-, la adjudicación a una sociedad mixta, previo concurso con doble objeto y con al menos el 40 por ciento para el sector privado, así como para sociedades "in house", se admitiría exclusivamente para municipios con más de 50.000 habitantes, mientras que para los demás se debería proceder a la adjudicación exclusivamente previo concurso y sin poder recurrir al partenariado. Las posteriores intervenciones legislativas no han resuelto el tema.

19 Sobre el tema de la disciplina de los servicios públicos locales después de la Ley de estabilidad, véase: G. Guzzo, Brevi riflessioni sui nova dei SPL dopo la legge di stabilità n. 183/2011, en www.giustamm.it; $n^{\circ}$ 12-2011; M. Pani, I servizi pubblici locali a rilevanza economica: luci e ombre dopo il decreto legge 138/2011 e la legge di stabilità, in www.lexitalia.it, nº 1-2012; C. Volpe, Servizi pubblici locali e legge di stabilità, en www. giustamm.it, n¹2-2011; C. Viviani e S. Roberto, La nuova disciplina dei servizi pubblici locali di rilevanza economica: la concorrenza tra liberalizzazioni e diritti di esclusiva, en Urbanistica e Appalti, 2012, 39. 
— "garantizar, mediante un sistema de benchmarking, la mejora progresiva de la calidad y eficiencia de gestión de los mismos servicios".

Como consecuencia de dichas nuevas normas, se han reforzado el papel y los contenidos de la resolución marco de las entidades locales condicionando a su aplicación la posibilidad de asignar derechos de exclusividad (o privativos) y ampliando (mediante la conjunción añadida arriba referida "también” a la norma que preveía el envío a AGCM para el Informe anual) los poderes potenciales de intervención de la autoridad garante.

A este respecto conviene indicar la ampliación decisiva de los poderes de la Autoridad, reforzados ulterior y significativamente por la introducción del nuevo Art. 21-bis de la Ley n² 287/1990, añadido por el Art. 35 del D.L. $n^{\circ}$ 201 del 6 de diciembre de 2011 (Ilamado Decreto "salva Italia"), que ha previsto la legitimación para actuar ante los tribunales contra actos administrativos generales, los reglamentos y las medidas de cualquier administración pública que violen las normas que protegen a la competencia y al mercado ${ }^{20}$.

El papel activo que la Autoridad empieza a desempeñar encuentra confirmación en la "Notificación sobre las propuestas de reforma de competencia según la Ley anual sobre el mercado y la competencia-Año 2012 (Ref. S. 1378)", enviada a los Presidentes de las Cámaras, al Presidente del Consejo de Ministros y al Ministro para el Desarrollo Económico, la Infraestructura y los Transportes el 5 de enero de 2012.

La letra a) del citado Art. 9, párrafo 2, retomando la norma contenida en el Art. 23-bis, párrafo 6, del D.L. $n^{\circ}$ 112/2008, establece además que la entidad local, en el momento de aplicar la mencionada resolución, también debe valorar la oportunidad de proceder con la adjudicación simultánea, mediante procedimiento público, de una pluralidad de servicios públicos locales en los casos en los que se pueda demostrar que una elección de esta índole puede generar resultados económicamente ventajosos.

El "proyecto" de liberalización se potencia ulteriormente con la previsión de un decreto interministerial que se ha de aplicar antes del 31 de enero de 2012 (ahora prorrogado al 31 de marzo), destinado a definir los criterios para la verificación de la factibilidad de la gestión de la competencia y la aplicación de la resolución marco establecida en los párrafos 1 y 2 del mismo Art. 4, y las medidas y modalidades necesarias para garantizar la aplicación plena de las normas establecidas en el Art. 4 D.L. 138.

De esta forma, para dirigir y uniformizar la actividad de las entidades en la línea de liberalización arriba referida, se garantiza que la resolución marco sobre la situación de la competencia de los servicios públicos locales, que las entidades locales deberán aplicar para el 13 de agosto de 2012 (es decir, a los doce meses de la entrada en vigor del D.L. 138) y, en todo caso, "antes de proceder al otorgamiento y la renovación de la gestión de los servicios", asuma contenidos precisos y se mueva en espacios predefinidos, sobre todo en relación con el análisis de mercado previsto ${ }^{21}$.

La Ley 183 de 2011, además, ha desvirtuado la prohibición de extraterritorialidad para las sociedades mixtas, siempre y cuando estén constituidas según el párrafo 12 del citado Art. 4 del D.L. n 138/2011, de modo que la disciplina de la gestión de los servicios públicos locales se diversifica de nuevo -mientras que en el pasado se había alineado- de la indicada por el referido Art. 13 del D.L. $n^{\circ} 223$ del 4 de julio de 2006, convertido, con modificaciones, en la Ley $n^{\circ} 248$ del 4 de agosto de 2006 , en la parte en la que prevé que las sociedades de capital íntegramente público o mixto, constituidas o participadas por las administraciones públicas regionales y locales para la producción de servicios instrumentales de la actividad que éstas desempeñan, deben obrar exclusivamente con las entidades constituyentes o participantes o adjudicadoras y no pueden realizar prestaciones (obras, servicios y suministros) a favor de otros sujetos públicos o privados ni participar en otras sociedades o entidades.

Como ya se ha adelantado, algunas modificaciones introducidas por la Ley 183 corresponden a las observaciones de la Autoridad garante de la competencia y del mercado en la referida Notificación del 26 de agosto.

En especial, además de las que ya se han indicado, se mencionan la introducción de la prohibición de fraccionamiento del servicio y de su adjudicación, impidiendo el recurso a dicha medida para entrar en los límites de admisibilidad de la gestión "in house", en todo caso, se recuerda, reducida hoy a 200.000 euros anuales.

De gran interés es también la norma (letra $m$ del Art. 9, párrafo 2, de la Ley 183), que introduce el párrafo 33bis al Art. 4 del D.L. 138, respondiendo a la indicada carencia de "medidas de garantía de eficiencia y de calidad en la gestión del servicio" bajo la forma de valoraciones de "benchmarking" que, con independencia de la naturaleza (pública o privada) del gestor, acompañen al proceso de reforma de los servicios públicos locales.

20 Según el párrafo 2 del citado Art. 21-bis, "La Autoridad garante de la competencia y del mercado, si considera que una administración ha procedido a una actuación que viola las normas para la protección de la competencia y del mercado, emite un parecer motivado en el que indica los perfiles específicos de las violaciones detectadas. Si la administración pública no se conforma en los sesenta días posteriores a la comunicación del parecer, la Autoridad puede presentar, a través de la Abogacía del Estado, el recurso dentro de los treinta días siguientes".

21 C. Volpe, cit. 
La norma, de máxima relevancia en la política de liberalización de los servicios públicos locales, con objeto de asegurar la mejora progresiva de la calidad de gestión de los propios servicios y de realizar valoraciones comparativas de las diversas gestiones, contempla la obligación para las entidades adjudicatarias de hacer públicos los datos que conciernan al grado de calidad del servicio prestado, el precio medio por usuario y el alcance de las inversiones realizadas, así como cualquier información ulterior necesaria para las finalidades antedichas.

Otras modificaciones aspiran a resolver ulteriores perfiles de criticidad detectados en relación con el régimen diseñado por el mismo Art. 4.

En primer lugar, se reinserta la cláusula de prevalencia de las disposiciones generales, introducidas por el D.L. 138, respecto de aquellas de sectores incompatibles. Por consiguiente, también en el transporte público local, encuentran ya aplicación el párrafo 13 del Art. 4 del D.L. $n^{\circ} 138$ en cuanto a las condiciones que legitiman el recurso a la adjudicación "in house" y el párrafo 32 sucesivo sobre el régimen transitorio.

Finalmente, el D.L. sobre liberalizaciones ha eliminado de los servicios excluidos el transporte ferroviario regional, aún exceptuando los contratos ya adjudicados por un periodo de seis años (pero con exclusión de la renovación ya prevista por una controvertida norma especial, insertada en la Ley $n^{\circ} 133$ de 2009). En relación con la disciplina transitoria prevista en el párrafo 32, la letra f) del Art. 9, párrafo 2, de la Ley n 183/2011 -sustituyendo algunas palabras contenidas en la letra d) del mismo párrafo- aclara, en primer lugar, que la privatización de las sociedades de participación pública cotizadas en bolsa también se aplica también en presencia de pactos parasociales.

La siguiente letra g) -insertando el párrafo 32-bis- asigna a los delegados provinciales el cometido de verificar el correcto cumplimiento, por parte de las entidades locales, de la aplicación del régimen transitorio previsto en el párrafo 32, estableciendo que, en caso de incumplimiento, el delegado provincial asigna a las entidades incumplidoras un plazo perentorio en el cual poner remedio. Transcurrido dicho plazo, se prevé que el Gobierno, si se dan los supuestos, ejerza el poder sustitutivo según el Art. 120, párrafo segundo de la Const. y según las modalidades previstas por el Art. 8 de la Ley $n^{\circ} 131$ del 5 de junio de 2003.

La norma, que encuentra un antecedente muy reciente en el Art. 16, párrafo 28, del mismo D.L. $138^{22}$, tiende a resolver el antiguo problema de las entidades locales que, a pesar del cese de la adjudicación dispuesta "ex lege" en el antedicho párrafo 32 del Art. 4, no proceden a una nueva adjudicación (con la convocatoria de la licitación).

Antes de concluir este análisis sobre la evolución normativa en materia de sociedades mixtas, que desemboca necesariamente en el de las más recientes intervenciones de reforma de los servicios públicos locales y en el sincero auspicio de que, por fin, el sistema se estabilice y los términos de adaptación a las nuevas normas no sigan posponiéndose, como lamentablemente ha sido tradición, merece que se destaquen, justamente bajo esta perspectiva de apertura efectiva al mercado, las nuevas normas (introducidas por el D.L. sobre liberalizaciones) para garantizar que los concesionarios y adjudicatarios de servicios públicos locales, tras un requerimiento específico, suministren a las entidades locales que decidan convocar la licitación para la adjudicación del servicio correspondiente los datos sobre las características técnicas de las instalaciones e infraestructuras, su valor contable inicial, las revalorizaciones y las amortizaciones y cualquier otra información necesaria para definir las convocatorias. Sin perjuicio de lo previsto en los artículos 3 de la Ley n 287 del 10 de octubre de 1990 y 102 del Tratado sobre el Funcionamiento de la Unión Europea, la norma prevé que el retraso en la comunicación que supere el plazo de sesenta días desde la solicitud correspondiente y la comunicación de informaciones falsas constituyen un acto ilícito que el delegado provincial, a petición de la entidad local, sanciona con una multa administrativa, impuesta según la Ley $n^{\circ} 698$ del 24 de noviembre de 1981, por un mínimo de 5.000 hasta un máximo de 500.000 euros (sujeta a la jurisdicción del juez ordinario).

\section{CONCLUSIONES}

Por lo tanto, concluyendo, se puede observar que el proceso de liberalización en el sector de los servicios públicos locales, incentivado seriamente por la reforma de agosto, sale reforzado aún más por la Ley de estabilidad 2012 y por el D.L. sobre liberalizaciones. Las nuevas normas indudablemente se mueven en plena coherencia con el acuerdo manifestado por el Gobierno en la reciente carta de Italia a la Unión Europea del 27 de octubre de

22 Según el cual "Con objeto de verificar la persecución de los objetivos de simplificación y reducción de los gastos por parte de las entidades locales, el delegado provincial comprueba que las entidades territoriales interesadas hayan actuado, dentro de los plazos establecidos, según lo previsto por el artículo 2 párrafo 186, letra e), de la Ley n 191 del 23 de diciembre de 2009, y modificaciones posteriores, y por el artículo 14, párrafo 32, primera parte, del citado Decreto-ley $n^{\circ} 78$ de 2010, según la última modificación establecida por el párrafo 27 del presente artículo. En caso de que, en el momento del resultado de la comprobación el delegado provincial detecte la falta de actuación en cuanto a lo previsto por las normas indicadas en la primera parte, asigna a las entidades incumplidoras un plazo perentorio en el cual actuar. Transcurrido en vano dicho plazo, sin perjuicio de lo previsto por la segunda parte, encuentra aplicación el artículo 8, párrafos 1, 2, 3 y 5 de la Ley n 131 del 5 de junio de 2003 ". 
2011, en la que, en relación con dicho sector, se expresa la voluntad de aplicar normas para reforzar "el proceso de liberalización y privatización, previendo que no es posible atribuir derechos de exclusividad en los supuestos en los que la entidad local adjudicadora no proceda a la verificación previa de la factibilidad de un sistema de competencia en el mercado, es decir, de un sistema totalmente liberalizado" y prever "una ampliación de las competencias de la Autoridad garante de la competencia y del mercado, así como un sistema de benchmarking para garantizar la mejora progresiva de la calidad de gestión y realizar valoraciones comparativas de las diversas gestiones".

Esto es así, como ya se ha observado ${ }^{23}$, según el convencimiento, de origen comunitario, de que la protección de la libre competencia produce efectos benéficos no solo para el mercado y, por ende, para las empresas de sector que operan en él, sino también para los propios usuarios, destinatarios de los servicios, de los que debería contribuir a asegurar la eficiencia, la eficacia y la economicidad en interés de todos los protagonistas del sector: entidades públicas adjudicadoras, sujetos gestores y usuarios. En este sentido es significativa la norma de apertura de las modificaciones introducidas por el D.L. sobre liberalizaciones en el sector de los servicios públicos locales. Así, se afirma sobre todo que la organización del desarrollo de los servicios públicos locales, en ámbitos o sectores territoriales óptimos y homogéneos identificados también en relación con dimensiones tales como para permitir una economía de escala y una diferenciación aptas para maximizar la eficiencia del servicio, constituye un principio general del ordenamiento nacional al que las Regiones tendrán que conformarse según el Art. 117, párrafo 2, letras e) y s), de la Constitución antes del 30 de junio de 2012, so pena de que el Consejo de Ministros ejerza los poderes sustitutivos según el Art. 8 de la Ley nº 131 del 5 de junio de 2003.

Además, se añade que, a partir de 2013, la aplicación de procedimientos de adjudicación de los servicios públicos por parte de Regiones, Provincias y Municipios o de las entidades de gobierno local del ámbito o sector constituye un elemento de valoración del cumplimento de los mismos según el artículo 20, párrafo 3, del Decreto Ley $n^{\circ} 98$ del 6 de julio de 2011, convertido en la Ley $n^{\circ} 111$ del 15 de julio de 2011. Para dicho fin, la Presidencia del Consejo de Ministros, en el ámbito de los cometidos indicados en el artículo 5, comunica, en el plazo perentorio del 31 de enero de cada año, al Ministerio de economía y finanzas las entidades que han aplicado los procedimientos previstos por el presente artículo. En caso de falta de comunicación dentro del plazo arriba indicado, se prescinde del icho elemento de valoración del cumplimiento.

Asimismo, se indica que, sin perjuicio de los proyectos inherentes a los servicios públicos locales de relevancia económica cofinanciados con fondos europeos, las financiaciones a cualquier título concedidas a través de recursos públicos estatales según el artículo 119, párrafo 5 , Const., se atribuyen prioritariamente a las entidades de gobierno de los ámbitos o sectores territoriales óptimos, es decir, a los correspondientes gestores del servicio seleccionados mediante procedimiento público o de los cuales, en todo caso, la Autoridad de regulación competente ha verificado la eficiencia de gestión y calidad del servicio prestado sobre la base de los parámetros establecidos por la misma Autoridad ${ }^{24}$.

Sin embargo, queda abierta la cuestión de la compatibilidad constitucional de una elección que se contrapone al resultado del referéndum del 12 y 13 de junio de 2011, que, más allá de la mayor o menor toma de conciencia que tenían los votantes, ha expresado una voluntad derogatoria de las normas a favor de la competencia contenidas en el Art. 23 D.L. 112 y posteriores modificaciones e integraciones, y en el reglamento de actuación correspondiente.

Queda apartada la tesis (sostenida además por una doctrina muy autorizada ${ }^{25}$ ) que niega al resultado del referéndum la virtud de vínculo jurídico, pero la emergencia de superar la crisis económico-financiera, ciertamente apta para justificar la reforma de agosto y las modificaciones introducidas en sentido restrictivo de la Ley de estabilidad, resulta al fin y al cabo más difícilmente justificable ante las demoras temporales en la aplicación de la reforma, contenidas, según una praxis ya constante, en el D.L. sobre liberalizaciones. En otros términos, no parece fácil justificar con la emergencia la reproducción y la gravedad de medidas ya rechazadas por el cuerpo electoral y ya valoradas como "no necesarias para la comunidad" por el Tribunal Constitucional, cuya operatividad concreta se ha demorado más de un año. En definitiva, la cuestión queda más que abierta.

23 C. Volpe, cit.

24 El antedicho marco normativo se completa con una norma que favorece las privatizaciones, introducida por el Art. 5 del D.L. 138 repetidamente citado, que, bajo el título "Normas en materia de sociedades municipalizadas", introduce un mecanismo premiador a favor de la entidad privatizante para incentivar la transferencia de participaciones en sociedades gestoras de servicios públicos locales de relevancia económica, diferentes del servicio de aguas: los municipios, las provincias y las regiones que transfieren dichas participaciones podrán utilizar la cantidad de 500 millones de euros retirada por el Fondo de infraestructuras según el Art. 6-quinquies del D.L. $n^{\circ}$ 112/2008, convertido, con modificaciones, en la Ley $n^{\circ} 133 / 2008$, para gastar en la realización de nuevas infraestructuras. Se podrá disponer de la primera parte de la financiación, equivalente a 250 millones de euros, solo en 2013, mientras que la segunda parte, equivalente a otros 250 millones de euros, está prevista para 2014; a favor de las entidades que procedan a la transferencia, al 31 de diciembre de 2012 y 31 de diciembre de 2013 respectivamente. Se trata de una cuota de financiación no gravada por el pacto de estabilidad y que no podrá superar los ingresos de la transferencia realizada.

25 M. Luciani, Art. 75 Referendum, Bolonia, Zanichelli, 2005. 